\title{
Application of Solar Powered Automatic Water Pumping in Turkey
}

\author{
Mahir DURSUN and Semih OZDEN
}

\begin{abstract}
In this study, an automatic drip irrigation of dwarf cherry trees system with solar powered Brushless DC Motors (BLDC) has been designed and implemented in Zile District of Tokat Province of Turkey. One of motor was used for driving deep well pump which has been utilized for the purpose of water storing to a pool. The other one was used for driving centrifugal pump which has been utilized for the purpose of transferring of water waited in pool to drip irrigation. Optimum solar panels were selected according to calculated maximum power consumption of motors. The need of energy of BLDC Motors has been provided from solar panels and batteries. Sun tracking system was used for increasing efficiency of system. A DC-DC buck converter has been developed to feed motor and charge the batteries safely. Automation of system was provided with RF modules, soil moisture sensors and solenoid valves.
\end{abstract}

Index Terms - Brushless DC motor, drip irrigation, RF module, soil moisture sensor, solar energy

\section{INTRODUCTION}

Gradually decreasing energy sources and increasing demand for energy in recent years, makes more efficient and positive use of current water resources together with global warming and drought. $75 \%$ of the current fresh water consumption is agricultural irrigation in Turkey. Therefore, efficient water management plays an important role in irrigated agricultural cropping systems [1]. Since the sources utilized for the purpose of producing electricity are limited and their prices gradually increase researches for new alternatives for irrigation systems become more important.

Energy of pumps used for the agricultural irrigation is generally provided from electrical energy or fossil fuels. Since fossil fuels commence to annihilate besides its increasing of prices and hazards to environment alternative energy seeking efforts has become inevitable also in agricultural sector. Solar energy that is sensitive to environment, clean and requiring no maintenance is an alternative renewable energy source especially for countries like Turkey having a high amount of annual solar irradiation rate. When it is considered by means of requirement for irrigation the advantage of $\mathrm{PV}$ pumping systems is that water demand and increasing for sun shining are compatible

Manuscript received February 9, 2012; revised March 11, 2012. This work was supported in part by the Turkish Ministry of Industry and Trade named project 00228.STZ.2008-1 SANTEZ and Zile Mercantile Exchange.

M. Dursun is with the Department of Electrical \& Electronic Engineering, Faculty of Technology, Gazi University, Ankara, TURKEY (e-mail: mdursun@gazi.edu.tr).

S. Ozden is with the Department of Electrical, OSTIM Vocational High School, Gazi University, Ankara, TURKEY (e-mail: semihozden@gmail.com). characteristically [2]. In summer months obtained solar energy increases and also naturally water requirement of trees increases.

Photovoltaic powered water pumping systems (photoirrigation) have been studied by researchers in many years. Studies mostly concentrated on DC motors cause of energy obtained from solar panel is DC [3]-[8]. These are shown that better results were obtained for performance analysis [9]-[11]. Photoirrigation system has advantages than flooding irrigation. Some of these are, bringing utilization of water sources more efficient, preventing erosion and growing of weeds only by irrigating the requested areas [12], decreasing moisture stress [13], no operation cost, providing opportunity for local energy sources and exhibiting a parallel point of view with water requirement [14]. In terms of automation, developed wireless technologies, researches focused on automatic irrigation with sensors in agricultural systems [1],[15]-[25]. The advantages of using wireless sensor is to reduce wiring and piping costs, and easier to install and maintenance especially large areas [26].

Disadvantages of it are their high initial capital costs, the variability of the yield of the solar panels according to the prevailing weather conditions and in high temperature efficiency decreases [12]. At the current prices of PV modules, the cost of the proposed photovoltaic powered water pumping system is found to be less expensive than the cost of the conventional fuel system. The expected reduction in the prices of photovoltaic modules in the near future will make photovoltaic powered water pumping systems more feasible [14].

In this study an automatic photoirrigation system was designed at Zile District of Tokat Province of Turkey with two BLDC motors because of their high operating efficiency, brushless construction, maintenance free operation than the others. Optimum power of motors and solar panels were selected according to calculated maximum power consumption. Moreover BLDC motors, 48 PV arrays, a 100 tone water storage tank, 8 batteries and DC/DC converter were applied to irrigation of 1000 dwarf cherry trees planted to 8 decares has been realized with drippers each having a capacity of delivering 2 liters and kept under 3 bars pressure. Batteries are used in most of PV systems to perform two essential functions: power buffer between the arrays and load, and energy storage.

Designed system was provided site-specific management of irrigation systems with solar powered wireless acquisition stations. Portable 3 units and software named ValCon were developed. These units consist of a base station unit, solenoid valve unit and sensor unit. All of these units involve UDEA brand RF module, omni-directional antenna, $7 \mathrm{~V}-1.8 \mathrm{~W}$ solar 
panel and low power Microchip PIC18F452 micro controller chip. Additionally the sensor unit has soil moisture sensor, the valve has $12 \mathrm{~V}, 10 \mathrm{~W}$ normally-closed solenoid valve and battery. ValCon developed by authors with C\# language in Visual Studio.Net 2008 allows selection of control type (automatic or manual) and saving soil moisture data. MATH Design of Automatic Photoirrigation System

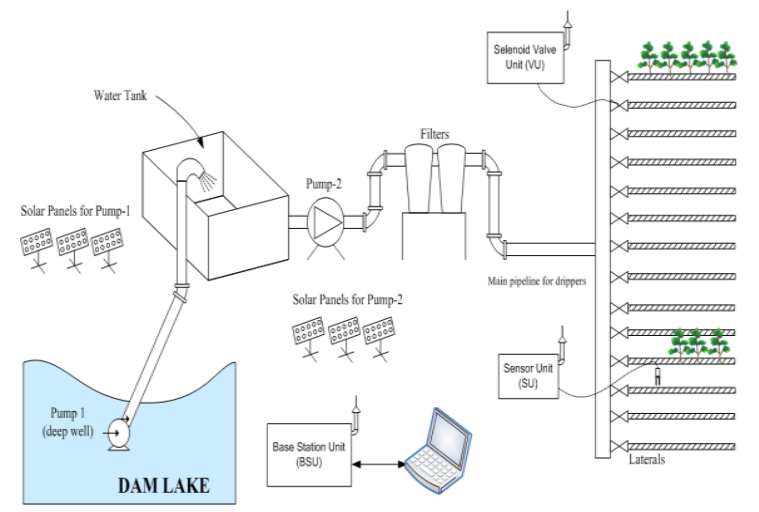

Fig. 1. Application of the system

\section{Design OF AUTOMATIC PHOTOIRRIGATION SYSTEM}

Automatic irrigation of 1000 pieces of cherry trees planted to 8 decares area in Zile District has been realized with system consisting of solar panels. Overall scheme of the system was shown in Fig. 1 and planted area was shown in Fig. 2. Deep well pump with BLDC-1 motor provided transport of water taken from Dam Lake to store and required pressure was provided for drip irrigation centrifugal pump with BLDC-2 motor with passing filters. Totally 3000 drippers were installed to the lateral pipe as 3 drippers for each tree by also considering the water demand of trees after they grow. With the drippers which has been selected with a capacity of $21 / \mathrm{h}$ water feeding the pressure is 3 bars dripping has been kept constant with a battery system. Only one set (solenoid valve unit, sensor unit and base station unit) is shown for automation of irrigation control. But totally 14 pieces of Sensor Unit (SU) and Solenoid Valve Unit (VU) were used for per lateral on reality. Decagon brand soil moisture was used for SU which evaluate data and send information (open or close) to valve unit. Position of valve was changed according to information received by SU. Also all data and position of valves were monitored by the software on a computer named ValCon which developed by authors. Also ValCon allows control of valves independently. The VU also involves $12 \mathrm{~V}, 10 \mathrm{~W}$ normally-closed solenoid valves and a battery.

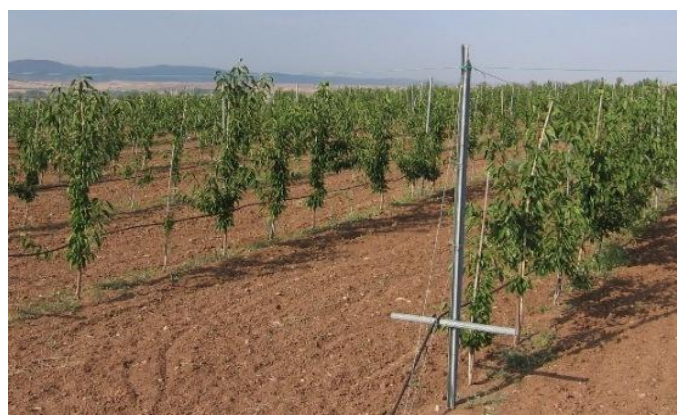

Fig. 2. Planted dwarf cherry trees

\section{A. Pumps and Motors}

BLDC-1 motor and panel connection type was given in Fig.3. Lorentz brand, $96 \mathrm{~V}, 3$ phases, $1.6 \mathrm{~kW}$ motor was utilized with its driver that is capable of directly connecting to solar panels. 24 pieces of panels each power of panels $80 \mathrm{~W}$ totally $1.92 \mathrm{~kW}$ installed to provide energy that is needed for BLDC-1. Motor is capable of filling the pool in 16-17 hours sunshine in cloudless weather conditions. Dam Lake and solar panels for BLDC-1 (pump-1) were shown in Fig. 4.

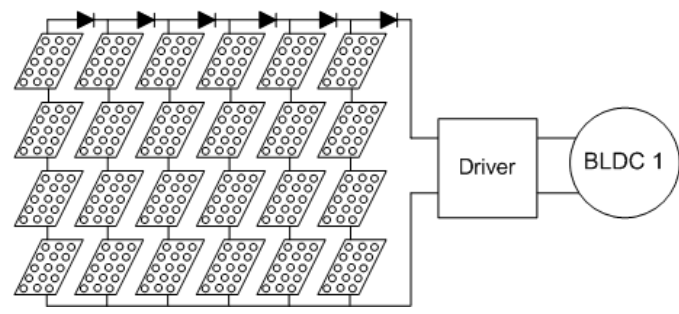

Fig. 3. BLDC-1 motor and solar panel connection

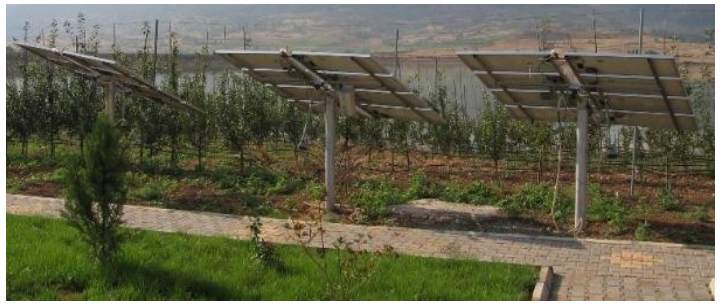

Fig. 4. Dam Lake and solar panels for BLDC-1

BLDC-2 motor with a power of $3 \mathrm{~kW}$ with $48 \mathrm{~V}$ has coupled with centrifugal pump. 24 piece of panels each having $80 \mathrm{~W}$ totally $1.92 \mathrm{~kW}$ has been assembled to provide energy that is needed for BLDC-2. However battery bank is added system to provide energy for motor in case sun irradiation is low. Installed battery power is $6240 \mathrm{~W}$ and can supply irrigation system without sun irradiation along 4 hours. Water obtained in the output of pumps, has been passed from required filters to prevent congestion of drippers and connected to the main pipe of drip irrigation. In Fig. 5, connection scheme of BLDC-2 motor was shown. Microcontroller is used control of converter PWM signals. Feedbacks of system are battery voltage and current, output of solar panels current and voltage, and output of converter current and voltage. These feedback values are sensed by microcontroller analog input.

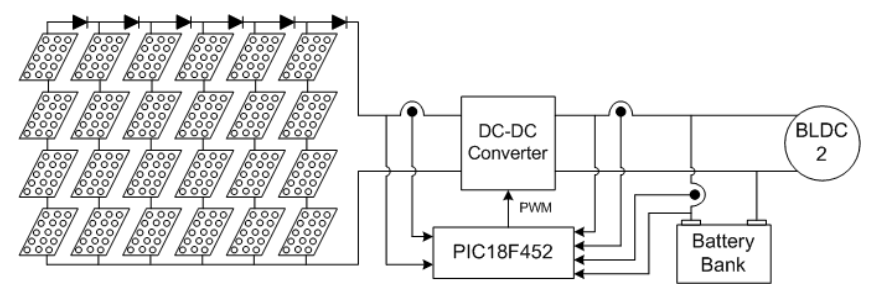

Fig. 5. BLDC-2 motor and panel connection

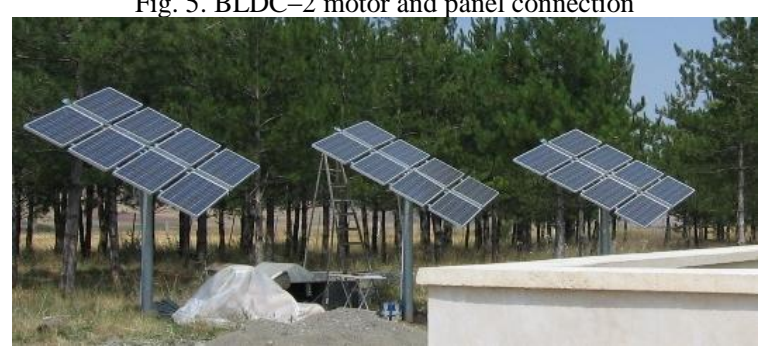

Fig. 6. Solar panels for BLDC-2 and water tank 


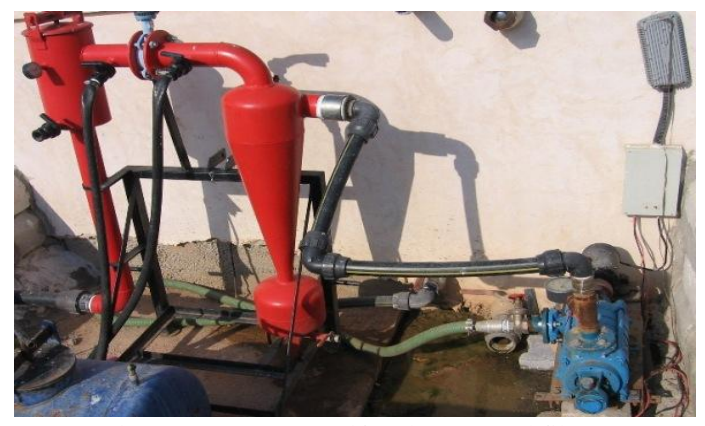

Fig. 7. BLDC-2, centrifugal pump and filters

Solar panels and water tank were shown in Fig. 6. BLDC-2, centrifugal pump and filters were shown in Fig 7.

\section{B. Converter and Control Circuit}

DC-DC converter, motor and PV was shown in Fig 8. Gate signals of MOSFETs were provided by PIC microcontroller. MOSFET-1 controls output voltage of solar panels. When system was started, firstly batteries voltage had been measured. If voltage of batteries is not less than value of deeply discharged, MOSFET-2 is opened. It also achieves only charge mode.

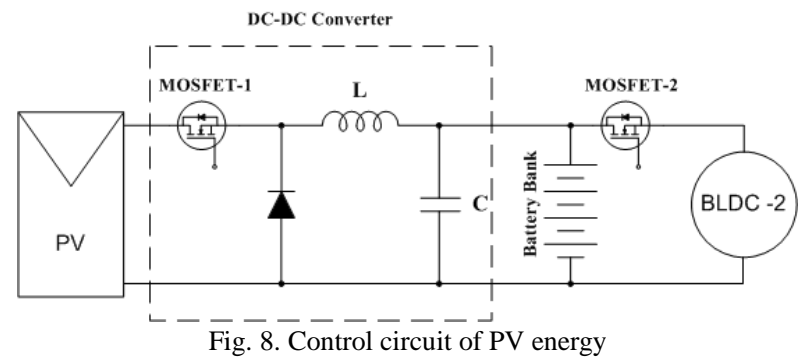

\section{Automation Units}

Solenoid Valve Unit (VU), Sensor Unit (SU) and Base Station Unit (BU) were designed to realize control of drip irrigation. All of these units involve RF module, antenna, $7 \mathrm{~V}$, $1.8 \mathrm{~W}$ solar panel and Microchip PIC18F452 (MCU). This MCU was selected due to low-cost, processor speed, low power requirements, rapid software development, and ease of system integration with custom circuits so that a cheap irrigation system could be achieved. UFM-M11 produced and marketed by UDEA Technology Inc. was selected as RF modules. This low power wireless module works $434 \mathrm{MHz}$ with UGPA-434 coded omni-directional antenna. Radio transmission range of module is 400-500 meters in environmental conditions. UFM-M11 uses Frequency-Shift Keying (FSK) modulation and maximum output of power is $10 \mathrm{dBm}$. Power consumption is $10 \mathrm{~mW}$ at $434 \mathrm{MHz}$ and current consumption is $17 \mathrm{~mA}$ receiver modes, $30 \mathrm{~mA}$ transmitter modes. RF wireless modules were adjusted to communicate with $9.6 \mathrm{Kbps}$ baud rate with MCU.

10HS coded pre-calibrated Soil Moisture Sensor of Decagon has been used to measure water content of soil in SU. Power consumption of $10 \mathrm{HS}$ is $12-15 \mathrm{~mA}$ and output voltage is $300-1250 \mathrm{mV}$ (independent of excitation voltage, 3-15 V DC). Measured analog data was sensed with ADC on PIC chip and evaluated. After defining valve position (on or off), this information was transmitted to VU. The 10HS measures the dielectric constant of the soil in order to find its volumetric water content (VWC) using a capacitance technique. Solar panel and SU included RF antenna, mounted soil moisture sensor and PCB of control was shown in Fig 9.

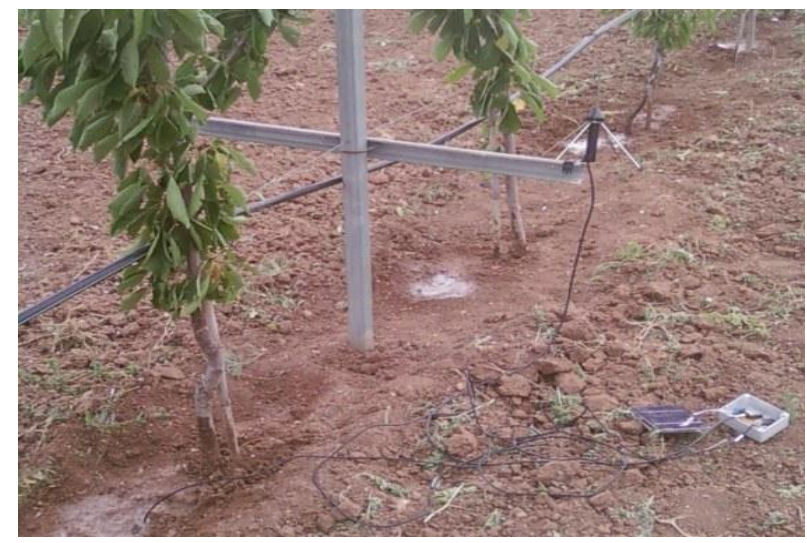

Fig. 9. Solar panel and sensor unit

\section{Software (ValCon)}

ValCon developed by authors with $\mathrm{C \#}$ language in Visual Studio.Net 2008 were used to control valves and save data Control method of irrigation (automatic or manual) could be selected by users. User interface of manual control was shown in Fig 10 and automatic control was shown in Fig 11. Data of sensors is shown in text box related to sensor number in both of two selections. ValCon allows saving sensor data, which is optional, in a file with extension of x.dat. Communication with RS-232 features can be selected to establish connection.

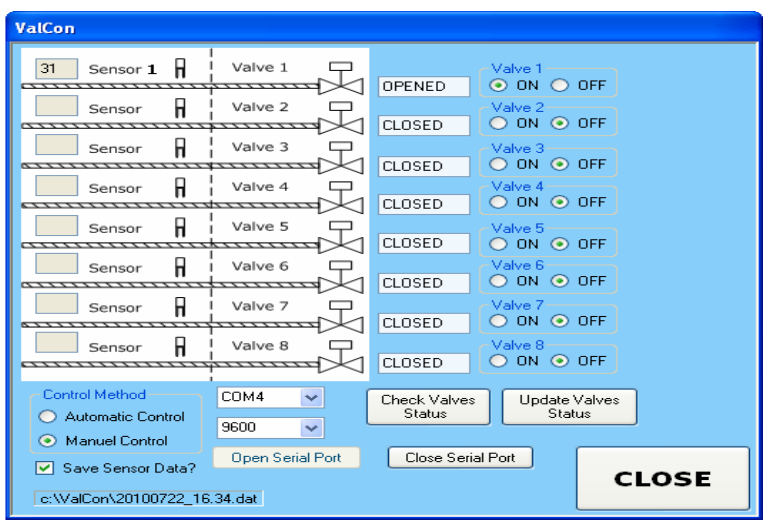

Fig. 10. User interface of manual control

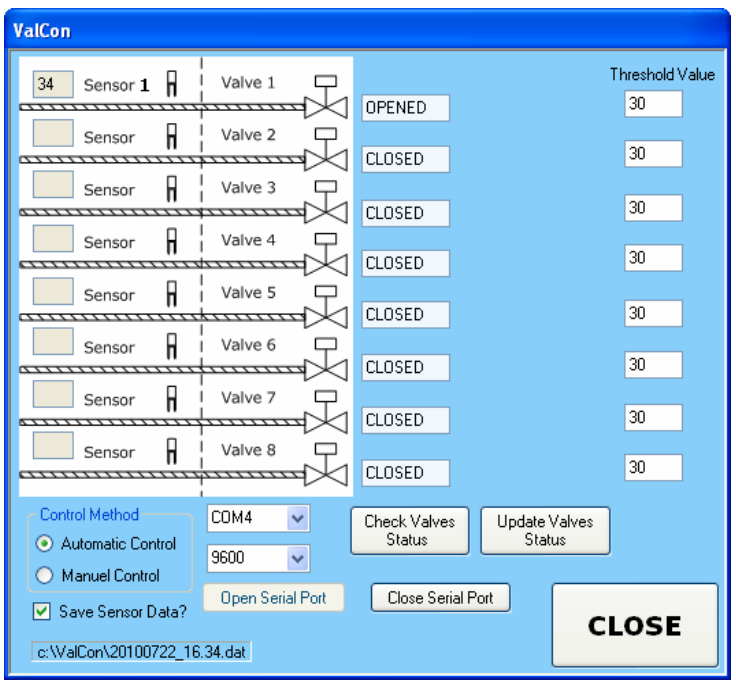

Fig. 11. User interface of automatic control 


\section{CONCLUSION}

In this study, automatic irrigation of dwarf cherry trees planted to 8 decares of area is realized with solar energy powered two different BLDCs and RF units. Motor with deep well pump has been utilized for water storage from Dam Lake to pool and motor with centrifugal pump is utilized for the purpose of transferring of water kept in pool to drip irrigation system. An installed capacity of $3.84 \mathrm{~kW}$ with 48 pieces of solar panels was designed to satisfy water requirement by growing of trees. Battery and water tank are utilized for the purpose of storing energy obtained from solar panels and in the meanwhile the stability of the system is also increased. Sun tracking circuit was utilized for the purpose of providing energy more efficiency than the installed power. Water demands of trees were defined with soil moisture sensors and were satisfied with output pressure and flow rate is achieved by pump. Site-specific irrigation provides effective management of scarce water resources and inhibits tree dead cause of too much irrigation. Also this sensor-based drip irrigation prevents moisture stress of trees, erosion and salification, provided less growth of weeds and decreased the amount of water utilized by these weeds. In addition to this system removes workmanship that is needed for flooding irrigation. Environmental pollution is prevented with renewable energy and energy production from local resources is encouraged. An advantage of system is that system needs no maintenance. The use of this photoirrigation system will be able to contribute to the socio-economic development in the Tokat region.

\section{REFERENCES}

[1] Y. Kim and R. G. Evans, "Software design for wireless sensor-based site-specific irrigation", Computers and Electronics in Agriculture, vol. 66, pp. 159-165, 2009.

[2] W. R. Anis and H. M. B. Metwally, "Dynamic performance of a directly coupled PV pumping system," Solar Energy, vol. 53, pp. 369-377, 1994.

[3] W. Lawrance, B. Wichert, and D. Hgridge, "Simulation and performance of a photo-voltaic pumping system," Power Electronics and Drive System, vol. 1, pp. 513-518, 1995.

[4] C. L. Putta Swamy, B. Singh, B. P. Singh, and S. S. Murthy, "Experimental investigations on a permanent magnet brushless DC motor fed by PV array for water pumping system," J. Sol. Energy Eng., vol. 122, pp.1663-1668, 2000.

[5] R. E. Katan, V. G. Agelidis, and C. V. Nayar, "Performance analysis of a solar water pumping system", Power Electronics, Drives and Energy Systems for Industrial Growth, vol. 1, pp. 81-87, 1996.

[6] M. Dursun and A. Saygin, "A switched reluctance motor driver with boost converter designed for a photovoltaic array irrigation system", Journal of The Institute of Science and Technology of Erciyes University, vol. 22, pp. 57-65, 2006.

[7] M. Dursun, "Education purpose switched reluctance motor driver for photovoltaic array irrigation system," in Proc. I. International Vocational and Technologies Congress, İstanbul, pp.595-601. 2005.

[8] M. Dursun and A. Saygin, "System Analysis of switched reluctance motor driver with boost converter for a photovoltaic array irrigation system," in 3rd Renewable Energy Sources Symposium, Mersin, pp. 57-62. 2005.

[9] M. Kolhe, J. C. Joshi, and D. P. Kothari, "Performance analysis of a directly coupled photovoltaic water-pumping system," IEEE Trans. on Energy Conv., vol. 19, pp. 613-618, 2004.

[10] S. Singer and J. Appelbaum, "Starting characteristics of direct current motors powered by solar cells," IEEE Trans. Energy Conversion, vol. 8, pp. 47-53, 1993.

[11] M. Kolhe, S. Kolhe, and J. C. Joshi, "Determination of magnetic field constant of DC permanent magnet motor powered by photovoltaic for maximum mechanical energy output," Renewable Energy, vol. 21, pp. 563-571, 2000.
[12] F. Cuadros, F. Lopez-Rodriguez, A. Marcos, and J. Coello, "A procedure to size solar-powered irrigation (photoirrigation) schemes," Solar Energy, vol. 76, pp. 465-473, 2004.

[13] P. C. Pande, A. K. Singh, S. Ansari, S. K. Vyas, and B. K. Dave, "Design development and testing of a solar PV pump based drip system for orchards," Renewable Energy, vol. 28, pp. 385-396, 2003.

[14] A. A. Ghoneim, "Design optimization of photovoltaic powered water pumping systems," Energy Conversion and Management, vol. 47, pp. 1449-1463, 2006.

[15] K. C. Stone, A. G. Smajstrla, and F. S. Zazueta, "Microcomputer-based data acquisition system for continuous soilwater potential measurements," Soil Crop Sci. Soc. Fla, vol. 44, pp. 49-53, 1985.

[16] V. M. Abreu and L. S. Pereira, "Sprinkler irrigation systems design using ISAMim”, ASABE, Paper No. 022254, 2002.

[17] Y. Kim, R. G. Evans, and W. M. Iversen, "Remote sensing and control of an irrigation system using a distributed wireless sensor network," IEEE Trans. Instrum. Meas, vol. 57, no. 7, pp. 1379-1387, 2008.

[18] Y. Kim, R. G. Evans, and W. M. Iversen, "Evaluation of closed-loop site-specific irrigation with wireless sensor network," J. Irrig. Drain. Eng, vol. 135, no. 1, pp. 25-31, 2009.

[19] R. W.Coates, M. Delwiche, and P. Brown, "Precision Irrigation in Orchards: Development of a Spatially Variable Microsprinkler System," Information and Technology for Sustainable Fruit and Vegetable Production (FRUTIC), pp. 611-624, 2005.

[20] E. T. Engman and N. Chauhan, "Status of microwave soil moisture measurements with remote sensing," Remote Sensing of Environment, vol. 51, pp.189-198, 1995.

[21] J. Mendoza-Jasso, G. O. Vargas, R. C. Miranda, E. V. Ramos, A. Z Garrido, and G. H. Ruiz, "FPGA-based real-time remote monitoring system," Computers and Electronics in Agriculture, vol. 49, pp.272-285, 2005

[22] F. R. Miranda, R. E. Yoder, J. B. Wilkerson, and L. O. Odhiamboc, "An autonomous controller for site-specific management of fixed irrigation systems," Computers and Electronics in Agriculture, vol. 48, pp. 183-197, 2005.

[23] A. Torre-Neto, J. K. Schueller, and D. Z. Haman, "Networked sensing and valve actuation for spatially-variable microsprinkler irrigation," in Proc. ASAE Annual International Meeting, USA, Paper No. 001158, 2000.

[24] N. Wang, N. Zhang, and M. Wang, "Wireless sensors in agriculture and food industry-Recent development and future perspective," Computers and Electronics in Agriculture, vol. 50, pp.1-14, 2006.

[25] Z. Zhang, "Investigation of wireless sensor networks for precision agriculture," in Proc. ASAE Annual International Meeting, USA, Paper No. 041154. 2004

[26] M. Dursun and S. Ozden, "A Prototype of PC Based Remote Control of Irrigation", International Conference on Environmental Engineering and Application (ICEEA), Singapore, IEEE Press pp. 255-258. 2010.

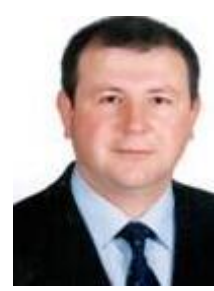

Mahir Dursun was born in 1970, in Corum, Turkey. $\mathrm{He}$ received a BS degree in 1993, an MSc degree in 1996, and a PhD degree in 2002 from Gazi University, Ankara, Turkey. He is currently an associate professor doctor at the Department of Electric Electronic Engineering, Faculty of Technology, Gazi University His research interests include motor design, modeling, motor control, switched reluctance motors, linear switched reluctance motors, brushless DC motors, DC-DC converters, matrix converters, FLC, Artificial neural networks, elevator motors, motor and centrifugal pump drivers, DSP, PLC, microprocessors and microcontroller programming, serial and parallel active power filters, and photovoltaic systems, photovoltaic irrigating systems, RF control and communications, and distance education material design.

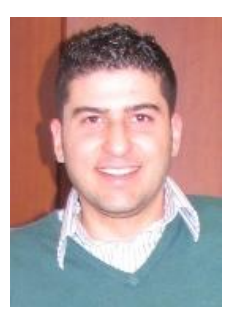

Semih Ozden was born in 1982, Aydın, Turkey. He received the BS degree in 2004, the MSc degree in 2007 from Gazi University, Ankara, Turkey and is now PhD student of Department of Electric Education, Gazi University. His research interests include photovoltaic systems, photovoltaic irrigating systems, switched reluctance motors, linear switched reluctance motors, motor control and controllers. His PhD's subject is "Design of $\mathrm{PV}$ powered smart drip irrigation system for dwarf cherry trees". 